\title{
Osteopetrosis-hypogammaglobulinemia syndrome
}

INSERM

\section{Source}

INSERM. (1999). Orphanet: an online rare disease and orphan drug data base.

Osteopetrosis-hypogammaglobulinemia syndrome. ORPHA:178389

Osteopetrosis-hypogammag lobulinemia syndrome is an extremely rare primary bone dysplasia with increased bone density disorder characterized by severe osteoclast-poor osteopetrosis associated with hypogammaglobulinemia. Patients typically present infantile malignant osteopetrosis (manifesting with increased bone density, bone fractures, abnormal eye movements/visual loss, nystagmus), hematologic abnormalities with bone marrow failure (e.g. anemia, hepatosplenomegaly) and immunological deficiency (manifesting as recurrent respiratory infections) associated with reduced immunoglobulin levels due to impaired peripheral B cell differentiation. 